theorists. Some further difficulties could have been avoided by even brief comparisons with other theories. Others stem from inadequacies in reflex theory itself. This is particularly obvious in the classification of res. ponses into major groupings which have neither functional nor causal coherence, like that of "preservative reflexes", which range from defaecation to parental behaviour. However, any serious attompt to understand the theses developed by Konorski can hardly fail to be rewarding.

One of the most interesting of these is the concept of "anti-drives". This draws a very elear distinction, which is quite ignored by most theories, betweon the behaviour shown when working for food or expecting a conditioned stimulus for food ("hunger") and the relaxed state, with feeding reflexes like salivation, which conditioned stimuli for food or food itself produce. Konorski, very properly, distinguishes the second or feeding state from that of satiation and goes on to suggest that "hunger" and "feeding" in these special senses, both depend on lateral hypothalamic activity, and are abolished by satiation. Some of the further developments of the concept are confusing. Thus it eventually turns out that there are three anti-drive states for hunger (feeding, satiation and extinction), all of which can provide reward by inhibiting hunger. Here, as throughout the book, nearly all the suggestions have the great merit that they so concretely propose physiological procosses or functions for brain structures that, right or wrong, they at once suggest new experiments. An excellent example is the idea that there are two classes of taste receptors: on-receptors which produce feeding reflexes, and off-receptors which cause a rebound of hunger after swallowing.

A very valuable, and, to a reader accustomed to American stimulus-responso theory, a rather unexpected feature of Konorski's approach is the way in which important information is derived from detailed obsorva. tion of the muscular movements involved in conditioned responses rather than of the frequency with which such responses aro given under various procedures. A good case is made for the idea that only responses which are due to a centrally initiated motor command can be conditioned. Movements which are produced either entirely by passive flexion or by stimulation of efferent pathways are not conditionable. Even more striking is the demonstration by Konorski's group that limbs which have been made useless in normal locomotion by section of all sensory nerves are still used to perform conditioned responses which remain just as stable as before the operation. Such conditioning of a motor command which lacks any proprioceptive feedback becomes particularly interesting when the effects of lesions of the basal ganglia of the forebrain (striatum) are considered. Such lesions abolish the use of even simple acts like locomotion or turning right or left as conditioned responses. Konorski suggests, as a result, that the striatum contains the "kinaesthetic units" which control simple conditionable motor acts. More complex conditioned responses depend on the sensorimotor cortex. A more radical hypothesis would be that the striatum is concerned in the initiation of all conditioned motor commands, whethor complex or simple.

Other readers may find their interest especially aroused by quite different topies. One excellent example is Konorski's use of introspection as one means of investigating the role of sensory images as intermediates in conditioning, which he invokes in animals as well as men. He argues further that transient memory is best thought of as concerned with the maintenance of such images rather than with the essential first step in formation of a permanent memory trace. This is of interest in a second connexion because it is one of the few places where a functional system which might be common to all drives is considered. It is to be regretted, for example, that there is no discussion of the control of attention shift, and of the work of Grastyan and others, in this connexion, on the hippocampus.
Inteqrative Activity of the Brain also deserves wide use as a systematic account of the natural history of conditioned reflexes. It can be used to discover exactly what types of stimuli have been used as conditioned stimulus, or what sorts of changes in their significance can easily be made, and which are almost impossible. Konorski uses such systematic treatments, often in conjunction with direct experiment, to show how it is already possible to relate some processes involved in acquiring a conditioned reflex to particular brain areas. Perhaps the best summary of such discussions is that learning depends on changes in a variety of structures, which may be different for different conditioned reflexes. The search for the engram seems likely at last to become identical with the study of the functioning of the whole brain.

R. J. Andrew

\section{MIND AS MACHINE}

\section{The Cerebellum as a Neuronal Machine}

By John C. Eccles, Masao Ito and János Szentágothai. Pp. viii +335 . (Berlin and New York: Springer-Verlag, 1967.) 68 DM.; $\$ 17$.

RECENT work on the cerebellum is important, not only for our understanding of cerebellar function, but also for the new light it has thrown on the mechanisms operat ing in the brain as a whole. The study of the cerebellum is favoured by its known function in the control of skilled movement and by the relatively simple anatomical structure of the cerebellar eortex, with the giant Purkinge cell as the only efferent type of neurone.

This book, which is clearly written and admirably illustrated, describes in some detail the new evidence obtained in the past fow years on the anatomical organization and electrophysiological properties of the cerebellar cortex. The first few chapters deal with the histological strueture and particularly with evidence coming from studies with the electron microscope. The later chapters describe the functioning of neuronal pathways. Finally, an attempt is made to assess the way in which tho cerebellum may function as a computing machine. In the present state of our knowledge the picture presented is inevitably incomplete. Neurochemical and pharmacological considerations are hardly mentioned and the discussion of learning in the performance of skilled actions, which is probably a principal function of the cerebellum. is dismissed in one short paragraph in which the authors speculate that learning may involve the microgrowth of dendritic spines. Nevertheless, this book is an outstanding achievement. It records a real advance in our understanding of the neural machinery in one important region of the central nervous system.

DEREK RICHTER

\section{MEETING ON THE MIND}

\section{The Human Mind}

Fdited by John Roslansky. (A Discussion at the Nobel Conference organized by Gustavus Adolphus College, St. Peter, Minnesota, 1967.) Pp. $x+164$. (Amsterdam: North-Holland Publishing Company, 1967.) 18 fl.; $36 s$.

Ar the third annual Nobel Conference a group of people from different fields were invited to concentrate on what seemed important to them in discussing the problems of the human mind. The resulting lectures, which aro now available in this book, are as varied as the personalities of the distinguished scientists and others who prepared them. Particularly successful is the contribution of F. O. Schmitt, who discussed "Molecular Parameters in Brain Function". Drawing on all the aceumulated data of the Neurosciences Research Program, he achieves a masterly 